\title{
AL DR. D. VICENT ORTELLS CHABRERA, PROFESSOR
}

\author{
JaVIer Soriano
}

Vaig conéixer a Vicent quan buscava un director de tesi pels corredors de l'edifici nou del CUC (Col-legi Universitari de Castelló). Coneixia la seua obra, ja nombrosa en temes d'urbanisme i evolució urbana, però no el coneixia personalment. Va obrir-me les portes del seu despatx com feia amb tot el món i vaig descobrir, primer, un director de tesi eficient, motivador $\mathrm{i}$ que sempre tenia un consell o una recomanació per trobar solucions a problemes grans o xicotets; posteriorment compartírem una amistat que encara continua i que ens va permetre treballar en perfecta harmonia en projectes d'investigació, publicació de llibres, organització de cursos d'estiu i congressos, preparació d'assignatures de llicenciatura i de grau, conferències, treballs de camp amb alumnat i moltes activitats més, fins i tot viatges de recerca a Mèxic o els Estats Units. Durant els anys d'estreta convivència vaig descobrir un professor amb una vocació sòlida, ferma i contagiosa, amb una passió per l'ensenyament, la recerca i el nostre patrimoni que és la clau per a triomfar en moltes activitats humanes seguint el seu exemple.

Vicent ha aconseguit el reconeixement del món acadèmic amb una trajectòria de compromís i treball continuat, primer en el CUC, on va ocupar el càrrec de secretari i també director de la Biblioteca; i després durant la gestació i consolidació de la Universitat Jaume I amb càrrecs de màxima responsabilitat en la gestió. Va formar part de l'equip redactor dels estatuts de la Universitat i va ser degà de la Facultat de Ciències Humanes i Socials en uns anys de constant creixement en titulacions i alumnat. A més, va assumir la direcció del seu departament, primer d'Humanitats i després d'Història, Geografia i Art, i va crear l'àrea de coneixement de Geografia Humana. Tot això en els anys de més càrrega de treball per la configuració de les noves estructures universitàries, la construcció de les noves llicenciatures i els programes de doctorat.

La seua trajectòria de professor, amb els inicis al CUC i la Universitat de València a finals dels 70, va continuar a la seu de Vila-real de la Universidad Nacional de Educación a Distancia (UNED) i, lògicament, ha assolit un 
Vaig conéixer a Vicent quan buscava un director de tesi pels corredors de l'edifici nou del CUC (Col-legi Universitari de Castelló). Coneixia la seua obra, ja nombrosa en temes d'urbanisme i evolució urbana, però no el coneixia personalment. Va obrir-me les portes del seu despatx com feia amb tot el món i vaig descobrir, primer, un director de tesi eficient, motivador $\mathrm{i}$ que sempre tenia un consell o una recomanació per trobar solucions a problemes grans o xicotets; posteriorment compartírem una amistat que encara continua i que ens va permetre treballar en perfecta harmonia en projectes d'investigació, publicació de llibres, organització de cursos d'estiu i congressos, preparació d'assignatures de llicenciatura i de grau, conferències, treballs de camp amb alumnat i moltes activitats més, fins $i$ tot viatges de recerca a Mèxic o els Estats Units. Durant els anys d'estreta convivència vaig descobrir un professor amb una vocació sòlida, ferma i contagiosa, amb una passió per l'ensenyament, la recerca i el nostre patrimoni que és la clau per a triomfar en moltes activitats humanes seguint el seu exemple.

Vicent ha aconseguit el reconeixement del món acadèmic amb una trajectòria de compromís i treball continuat, primer en el CUC, on va ocupar el càrrec de secretari i també director de la Biblioteca; i després durant la gestació i consolidació de la Universitat Jaume I amb càrrecs de màxima responsabilitat en la gestió. Va formar part de l'equip redactor dels estatuts de la Universitat $i$ va ser degà de la Facultat de Ciències Humanes $i$ Socials en uns anys de constant creixement en titulacions i alumnat. A més, va assumir la direcció del seu departament, primer d'Humanitats i després d'Història, Geografia i Art, i va crear l'àrea de coneixement de Geografia Humana. Tot això en els anys de més càrrega de treball per la configuració de les noves estructures universitàries, la construcció de les noves llicenciatures i els programes de doctorat.

La seva trajectòria de professor, amb els inicis al CUC i la Universitat de València a finals dels 70, va continuar a la seu de Vila-real de la Universidad Nacional de Educación a Distancia (UNED) i, lògicament, ha assolit un clímax professional a la Universitat Jaume I, on va apostar per unes novetats docents que encara no han estat igualades, com la creació d'assignatures eminentment geogràfiques en titulacions com Publicitat i Comunicació Audiovisual. Les desaparegudes Paisatge i publicitat o Localització d'exteriors suposaven una aportació innovadora que aplicava el coneixement territorial, paisatgístic i patrimonial per a trobar escenaris atractius en el complex món de la publicitat. La seua creació sorprenia en altres universitats i provocava admiració en el col.lectiu geogràfic espanyol. Malauradament, les tensions associades a la distribució de la càrrega docent i la lluita d'interessos entre titulacions van acabar amb unes propostes que, fins i tot, eren recolzades per l'alumnat. 
La seua recerca s'ha convertit en un referent en l'àmbit de l'anàlisi de l'evolució urbana, on és un autèntic especialista. Ha participat en la redacció de molts Plans Generals d'Ordenació Urbana de diferents localitats de la província de Castelló i ha difós els seus coneixements mitjançant nombroses publicacions, des de la tesi de llicenciatura apareguda l'any 1983 amb el títol La Plana de Castelló. Jerarquia i connexió urbana. Pocs anys més tard, la seua tesi doctoral Geografía urbana y del poblamiento de la Plana de Castelló va ser premi Ciutat de Castelló d'Humanitats (1986). Llegir avui eixa obra editada per l'Ajuntament ens permet admirar com podia aconseguir-se una publicació molt visual sense la gran quantitat de recursos tècnics que actualment tenim al nostre abast. Amb La ciutat preindustrial valenciana (1997) ampliava l'escala d'anàlisi i aportava material rellevant per a posteriors investigacions i aplicacions docents.

1. També ha fet importants incursions en el món d'Amèrica Llatina des de dues plataformes complementàries: el desaparegut Centro de Investigaciones de América Latina de la UJl y Medamérica, un grup de recerca de la Universitat de Barcelona creat i dirigit pel professor José Luis Luzón amb el que ha participat en diferents programes de doctorat de Brasil, Mèxic i altres països. Entre les aportacions més destacades cal esmentar un treball del sistema de ciutats d'Amèrica Central a la reunió de Washington de 1992 de The International Geographical Union (IGU) i un anàlisi de la tasca de les ONG en el desenvolupament local en Amèrica Central a la Regional Conference of Latin American and Caribbean Countries de La Habana (1995), també organitzada per la IGU.

2. La col.laboració amb Robert Kent, geògraf californià enamorat de Benicàssim des de la seva estada de recerca, també va ser profitosa amb la celebració el 2001 a Villa Elisa d'un congrés de CLAG (The Conference of Latin Americanist Geographers) i l'edició posterior de dues obres referent en els seus àmbits: Cities and urban geography in Latin America i Bridging cultural geography: Europe and Latin America.

Entre els projectes més significatius cal destacar els vinculats amb el món cartogràfic, amb un Atles de Castelló de la Plana fruit de la colaboració amb la Fundación Dávalos-Fletcher o l'elaboració/revisió del mapa de la província de Castelló escala 1:200.000 (versió en paper i versió en relleu) editat per la Diputació de Castelló. La col.laboració amb les administracions públiques també ha estat un dels èxits d'un treballador incansable, amb referències clau en el món editorial i bibliogràfic, com ara el llibre encomanat per l'Ajuntament de Castelló, La ciudad de Castellón de la Plana (1996).

La seua passió per viatjar, per no anar i tornar mai pel mateix camí, li va permetre escriure i dissenyar Solar y hábitat. El medio físico en la construc- 
ción de los núcleos castellonenses (1992). El llibre, editat per la Diputació en la seua col.lecció universitària, té una utilitat territorial òbvia i recorda un poc a les expedicions de Cavanilles al segle XVIII perquè l'autor va recórrer tota la província durant l'elaboració de l'obra.

Respecte a projectes de recerca, des del 2004 a 2009 van ser anys de màxima intensitat, amb la participació en dues investigacions finançades per la Generalitat Valenciana i un mateix escenari d'actuació, Amèrica Llatina: Plan estratégico de inversión en el patrimonio inmueble histórico con fines turísticos. El caso peruano i Estrategias comerciales históricas y actuales del sector cerámico entre la Comunidad Valenciana y México.

També ha aconseguit un reconeixement afegit, protagonitzat per la societat més pròxima, és a dir, els seus veïns, professorat i alumnat $d$ 'universitat i centres d'ensenyament secundari, així com tota la gent que estima el coneixement. Durant tots els anys d'estreta colllaboració i d'aprenentatge continuat, algunes anècdotes $m$ 'ho han confirmat. "Per casualitat saps el títol d'un llibre de tapes negres que té plànols de moltes ciutats de la Plana? És que a la biblioteca no van els ordinadors i no puc trobar-lo sense el títol i l'autor!" O... "estem fent una revista especial del comerç a Castelló i volem trobar un article de fa uns quants anys que va escriure Ortells i que no trobem". Probablement, Vicent Ortells sí ha estat profeta en la seua terra i, de fet, els seus treballs de Vila-real i la Plana són un referent.

És un professor que, després de la seua jubilació, serà recordat pel seu caràcter humanista, per la seua predisposició al diàleg i per la seva capacitat polièdrica, ja que a més de la seva especialització urbana va treballar un ampli ventall $d$ 'aspectes $i$ temes on el seu magisteri és digne $d^{\prime}$ 'admiració (sistemes de reg, demografia i poblament, economia i desenvolupament, gènere, patrimoni rural, paisatge, transports...). El seu ensenyament, les seues publicacions i els seus consells són un llegat que sempre tindrem a la nostra disposició. 